\title{
Mesoscale modeling study of the oceanographic conditions off the southwest coast of India
}

\author{
Vibeke E Haugen*, Ola M Johannessen and Geir Evensen \\ Nansen Environmental and Remote Sensing Center, Edvard Griegs Vei 3a, N-5059 Solheimsviken, \\ Norway. \\ *e-mail: Vibeke.Haugen@nrsc.no
}

\begin{abstract}
A high resolution model, using the Miami Isopycnic Coordinate Ocean Model (MICOM), has been implemented for the first time to study the seasonal circulation and coastal upwelling off the southwest Indian coast during 1974. This model is part of a model and data assimilation system capable of describing the ocean circulation and variability in the Indian Ocean and its predictability in response to the monsoon system.

Along the southwest coast of India the dominant coastal current is the reversing West Indian Coastal Current which is well simulated and described, in addition to the weaker undercurrent of the opposite direction. Upwelling of cold water, $4^{\circ} \mathrm{C}$ lower than offshore temperatures appear in April. The upwelling intensifies with the southwest monsoon and is simulated in accordance with in situ observations. Upwelling appears to be strongest off Cochin and Quilon, and the upwelling of cold water is seen together with a decrease in salinity in the model simulation.
\end{abstract}

\section{Introduction}

The southwest coast of India, like the rest of the Indian Ocean is an area which is strongly influenced by the monsoon winds. During the southwest (SW) monsoon, the surface current is southward and upwelling occurs along the coast. The current reverses during the northeast monsoon $(\mathrm{NE})$ and flows northward as the thermocline deepens. The continental shelf is one of the major fishing areas in India, due to the upwelling which leads to a supply of nutrients in the oxygen depleted waters which is continually being replenished by water from greater depths, giving a high production of phytoplankton.

Few investigations have previously been performed in this area and no continuous data sets are available. Banse (1968) established that upwelling of cold water takes place during the SW monsoon period, from May to October, by using hydrographic and sea level data. The most extensive research is reported by Johan- nessen et al (1981), with about 200 sections made between 1971 and 1975 covering the shelf between Ratnagiri in the north and Tuticorin in the south (figure 1), studying the seasonal variations of the water masses and upwelling in relation to fish stocks and plankton. They showed that upsloping started in March/April and that the seasonal variations were very repetitive from year to year. Hydrographic data which represent the conditions in June-August 1987 during the SW monsoon were used by Shetye et al (1990), with a follow up experiment during December 1987 and January 1988 (Shetye et al 1991). Shetye et al (1990) also established the existence of a northward flowing undercurrent along the continental slope during the SW monsoon, while Antony (1990) inferred its presence at $15^{\circ} \mathrm{N}$, Muraleedharan et al (1995) studied the undercurrent using in situ data between $8^{\circ}$ and $15^{\circ} \mathrm{N}$, and Stramma et al (1996) described it along an $8^{\circ}$ section from shipboard ADCP measurements.

Keywords. Mesoscale modeling; coastal upwelling; India. 


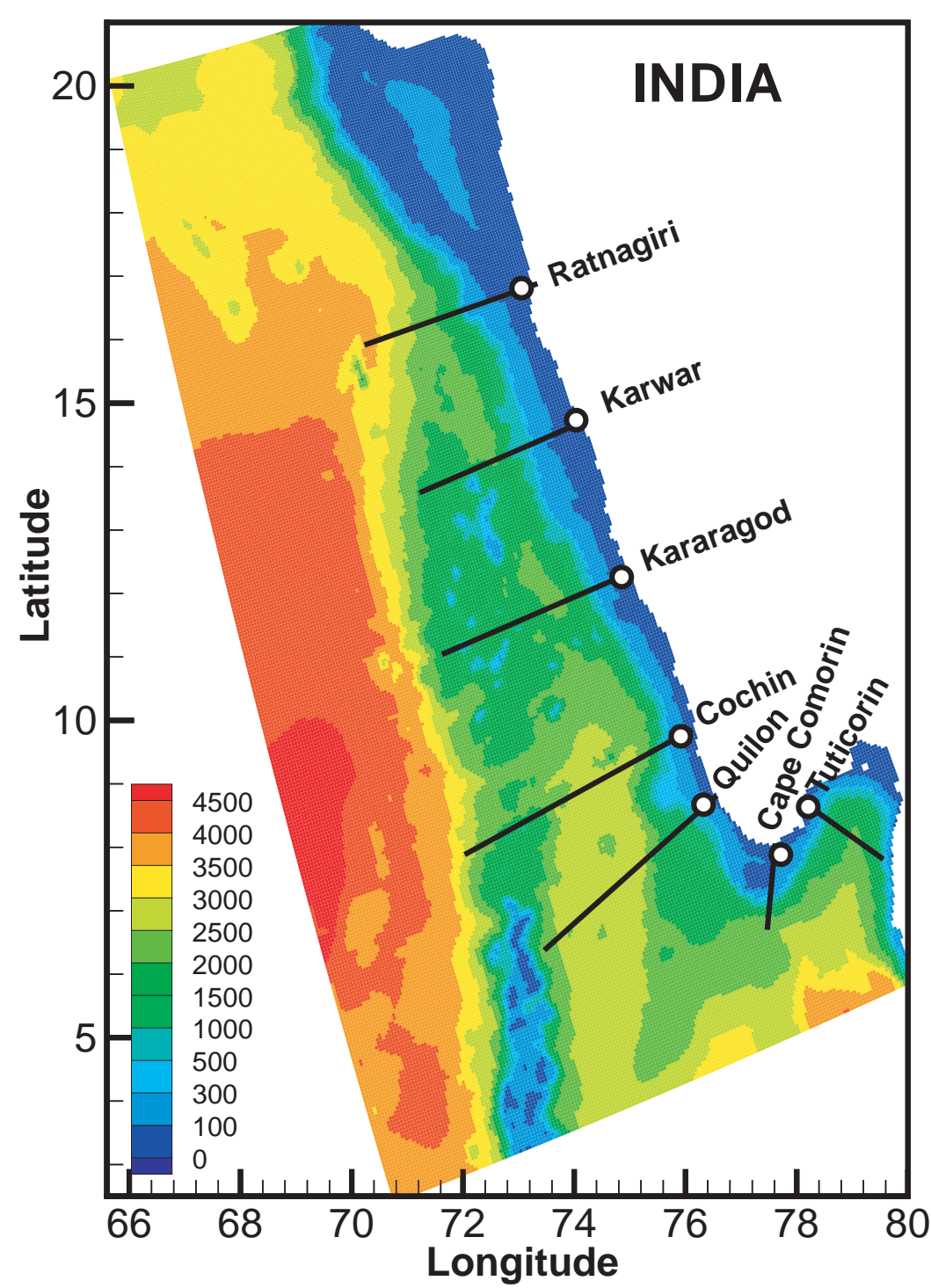

Figure 1. Bathymetry in model domain (isobaths given in meters). Bold lines represent sections used in the study, and circles represent time series in figure 11 .

We have established a model and data assimilation system (figure 2) for the Indian Ocean based on the Miami Isopycnic Coordinate Ocean Model (MICOM), to further improve the understanding and variability in the Indian Ocean and its predictability in response to the monsoon system. The system consists of the validated Indian Ocean model (Haugen et al 2002a), the Arabian Sea model, the high resolution coastal model, and the data assimilation method, the Ensemble Kalman Filter, implemented with the Indian Ocean model (Haugen and Evensen 2002). The coastal model was implemented in order to advance the understanding and improve the predictive capability of the circulation and upwelling conditions off the southwest coast of India which is an important region to the fishery of India. The year 1974 is chosen since this is a year covered by Johannessen et al
(1981) study. The model is forced on open boundaries by realistic water masses and transports generated by the nested model system.

The following section 2 describes the model setup and the nesting procedure. In section 3 surface and subsurface circulation in addition to a description of mesoscale eddies and the upwelling conditions is given. A discussion on possible generation mechanisms for the upwelling is also given in section 3. Finally in section 4 the conclusion is presented.

\section{Model setup}

The physical model used is based on the Miami Isopycnic Coordinate Ocean Model (MICOM), which is a dynamic-thermodynamic ocean general 


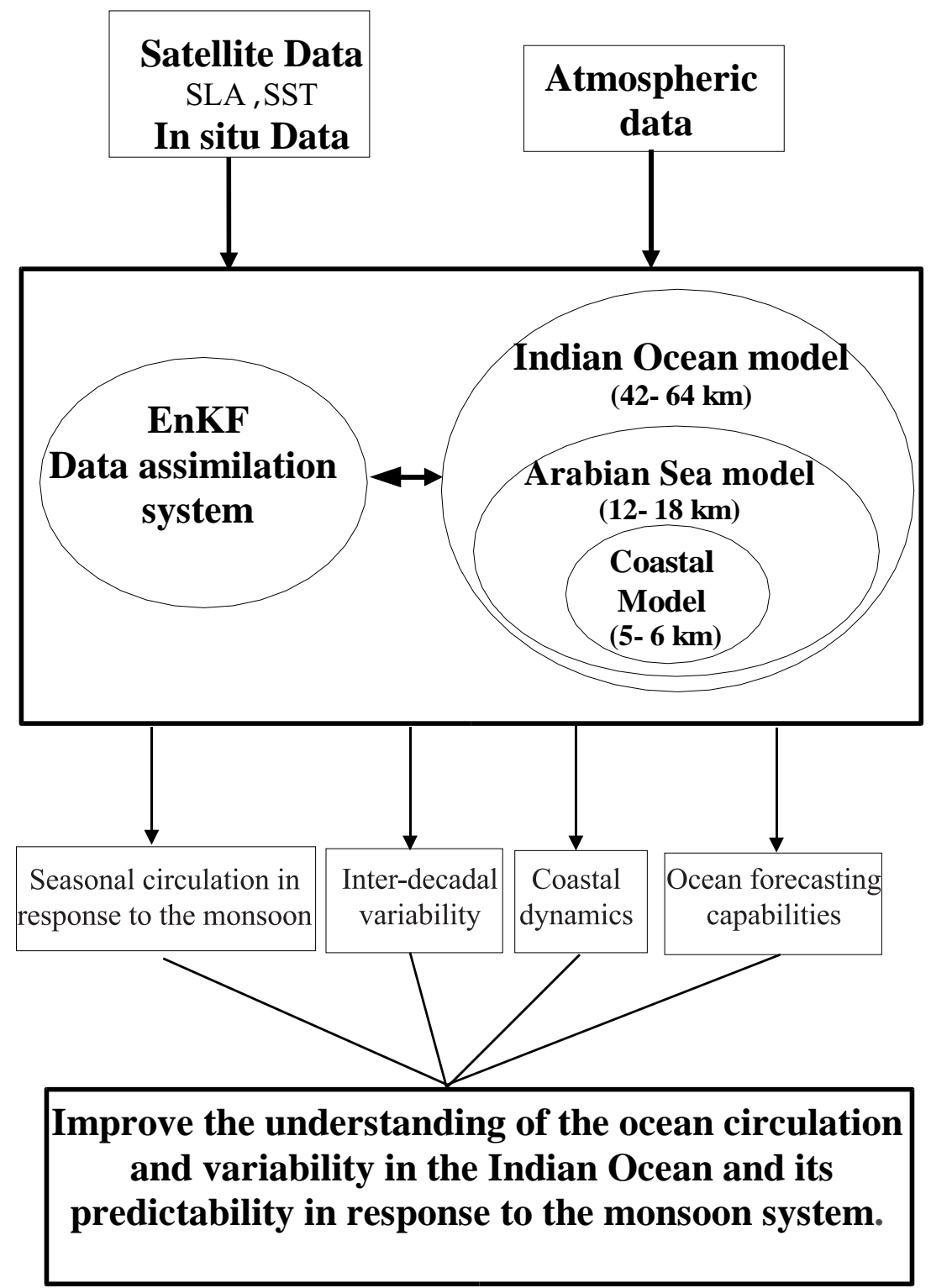

Figure 2. Illustration of the model system established for the Indian Ocean.

circulation model developed by Bleck et al (1992), and also Bleck and Boudra (1986), Bleck et al (1989) and Smith et al (1990) The model solves the primitive equations, using a split-explicit numerical scheme (Bleck and Smith 1990), and is in the horizontal discretized on a C-grid. In the vertical, MICOM uses potential density as the coordinate. The present implementation of the model has 15 layers based on densities from the study area. The upper layer is a mixed layer which interacts with the atmospheric forcing through freshwater and heat fluxes and the transfer of wind stress. It interacts with the interior layers through entrainment/detrainment processes when the mixed layer deepens/retreats, and the mixed layer depth is based on the bulk representation by Gaspar et al (1990). The different layers inter- act mainly through hydrostatic pressure forces, but there is also a vertical flux due to a specified diapycnal mixing.

An orthogonal curvilinear grid (Bentsen et al 1999) is used to enhance the resolution in the northern Indian Ocean. The large scale model has a resolution varying between 42 and $64 \mathrm{~km}$ (Haugen et al 2002a). However, the large scale model is clearly too coarse to properly represent the mesoscale processes in the coastal areas. To better simulate these, we have implemented a regional model also based on MICOM, for the Arabian Sea with enhanched resolution $(12-18 \mathrm{~km})$ which has been nested into the large scale model. A further down scaling to the west coast of India was obtained by using a third regional model, based on MICOM, with even higher resolution $(5-6 \mathrm{~km})$, 


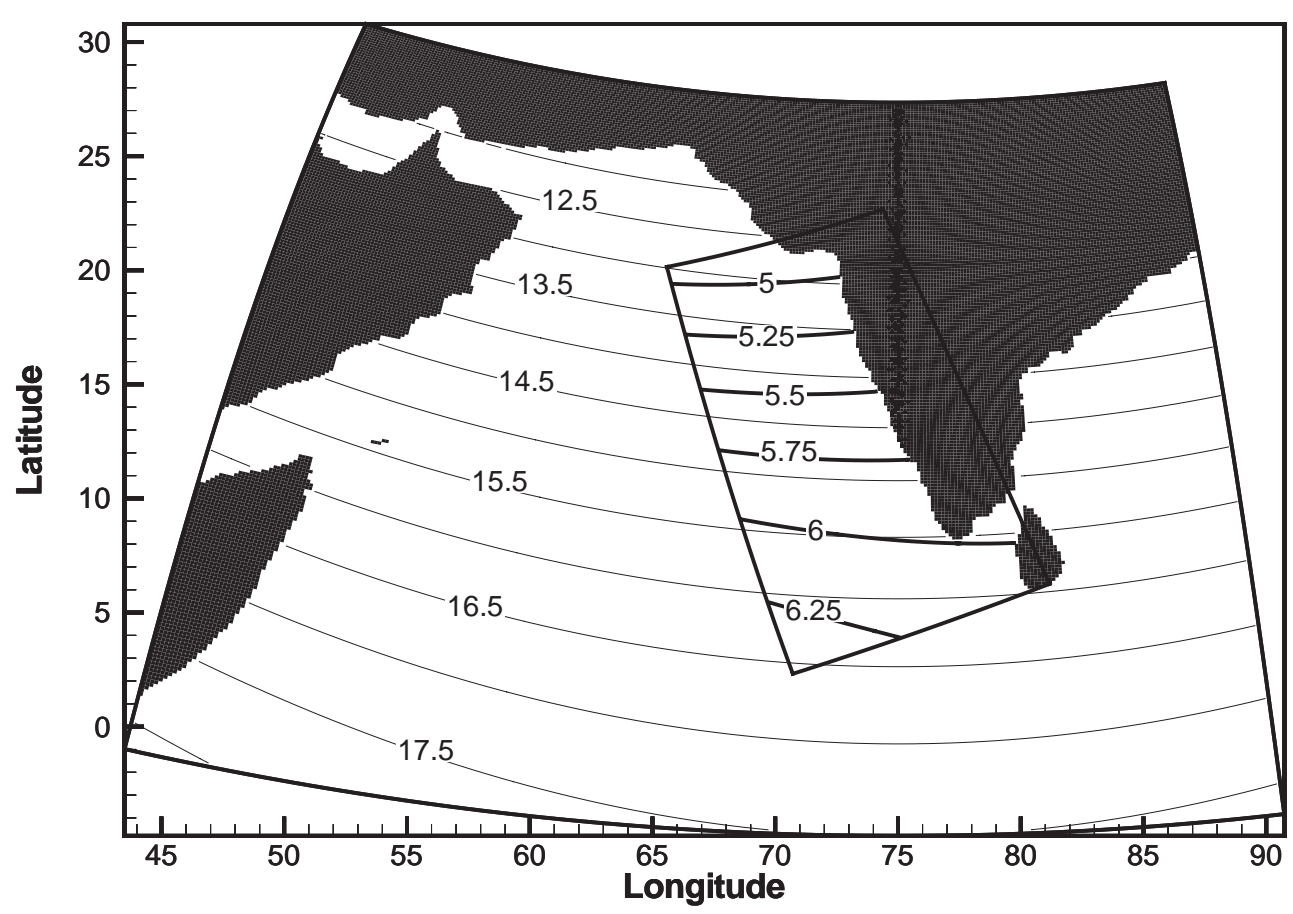

Figure 3. Model domain and grid size $(\mathrm{km})$ of the Arabian Sea model and coastal model used in the present investigation.

hereafter refered to as the coastal model, which was nested into the Arabian Sea model (figure 3). This model is used for the current investigation.

The large scale model was initialized using Levitus data, and spun up over 10 years using climatological monthly means of atmospheric forcing data. It was then run for 15 years using a mixture of climatological cloud cover from Comprehensive Ocean-Atmosphere Data Set (COADS), precipitation from Legates and Willmott (1990) and synoptic atmospheric fields (winds, air temperature, sea level pressure and relative humidity from National Centers Environmental Prediction (NCEP)), before it was used to make the nesting conditions to the Arabian Sea model. The NCEP data are available every six hours and have a spatial resolution of approximately $2^{\circ}$ by $2^{\circ}$. Data have been bilinearly interpolated to the model grid, and Hermitian interpolated in time. A weak surface relaxation of 50 days for salinity and temperature was used.

To avoid dealing with the problem of exactly specifying the boundary conditions in the nesting scheme, we use a boundary relaxation towards the outer model solution. This is a one way nesting scheme where the boundary conditions of the Arabian Sea model are relaxed towards the output from the large scale model (Haugen et al 2002a). The boundary conditions of the coastal model are again relaxed towards the output from the Arabian Sea model. For the slowly varying variables, i.e., baroclinic current, temperature, salinity and layer interfaces, this is an appropriate way to include the boundary conditions. For the barotropic variables the relaxation approach requires careful tuning to avoid reflection of waves at the open model boundaries. In MICOM the barotropic model is a hyperbolic wave equation for pressure and vertically integrated velocities. Following an approach outlined by Browning and Kreiss (1982, 1986) the barotropic boundary conditions are computed exactly while taking into consideration both the waves propagating into the regional model from the external solution and the waves propagating through the boundary formed from the regional model. The outer model writes the solution interpolated to grid points in the relaxation zone (20 grid points are used), of the inner model every day. The inner model reads the files every day and uses interpolation in time to specify the relaxation boundary condition every time step.

\subsection{Impact of nesting conditions and resolution}

The coastal model was initialized with fields from the Arabian Sea model. The mean kinetic energy (MKE) and mean eddy kinetic energy (EKE) was computed over January 1974 for the two models (figure 4). The MKE $\left(\mathrm{cm}^{2} / \mathrm{s}^{2}\right)$ is a measure of the strength of the mean flow, and is in isopycnal coordinates given as:

$$
\mathrm{MKE}_{k}=\frac{1}{2} \frac{{\overline{u_{k} \Delta P_{k}}}^{2}+{\overline{v_{k} \Delta P_{k}}}^{2}}{{\overline{\Delta P_{k}}}^{2}}
$$




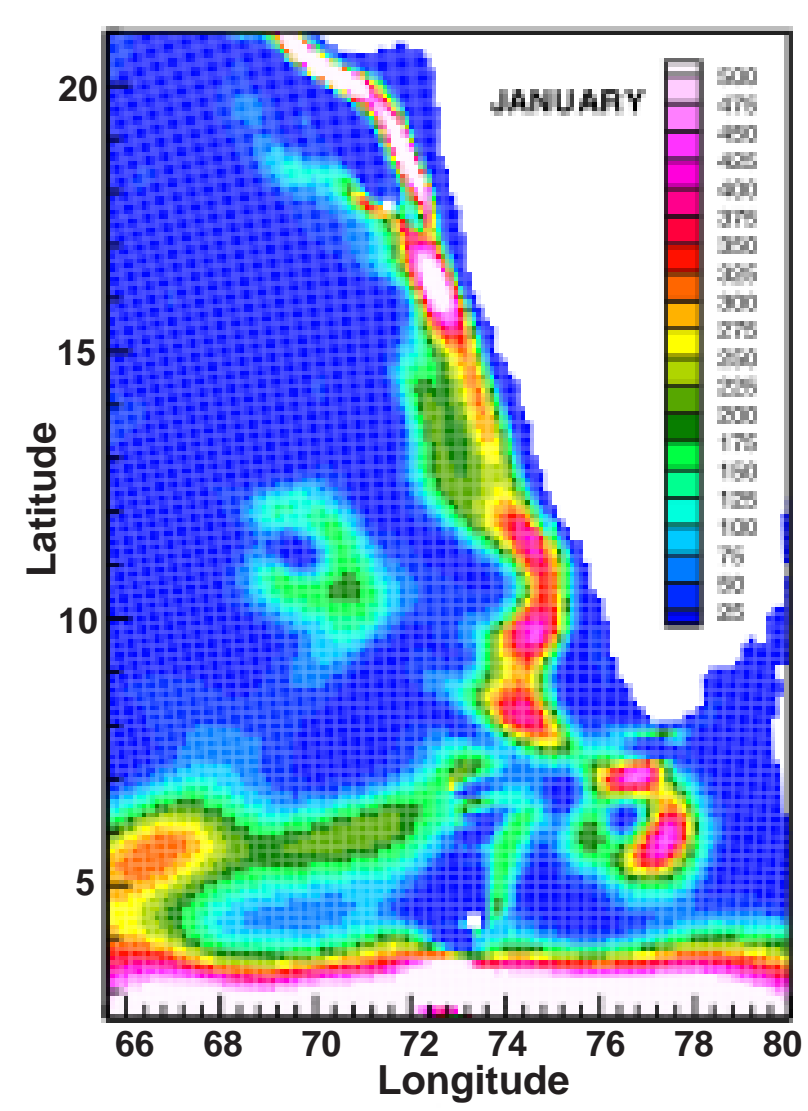

(a) MKE from the Arabian Sea model.

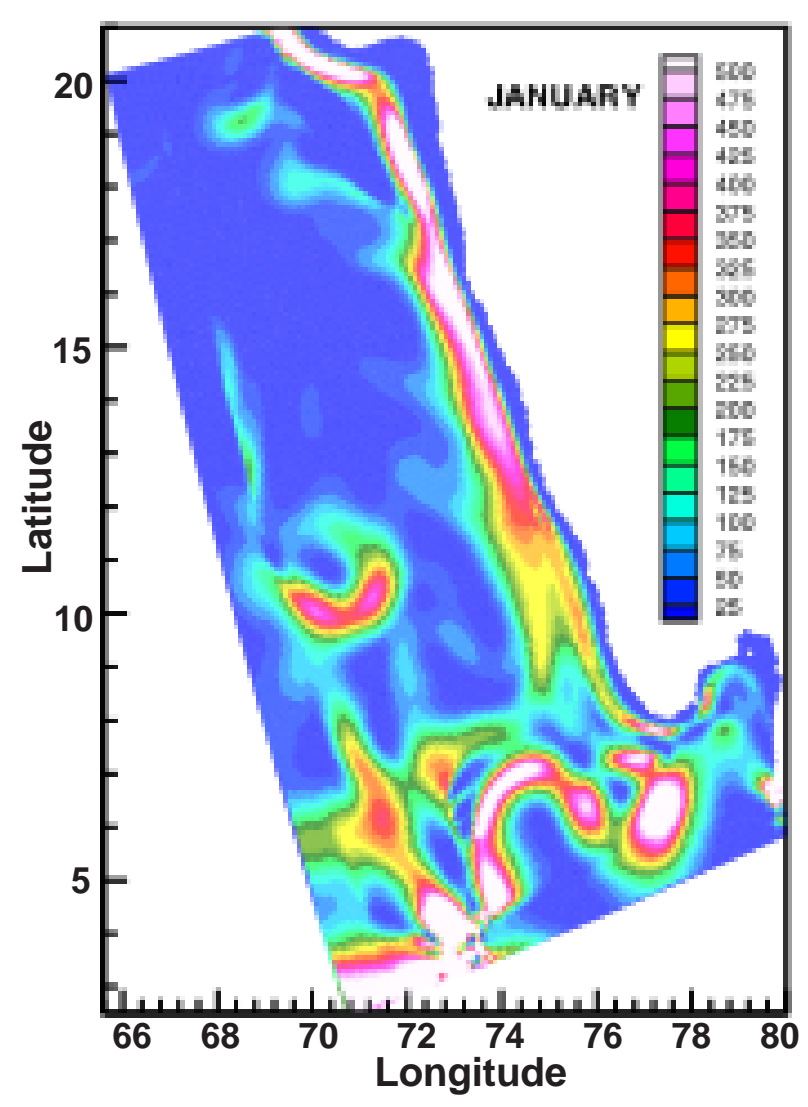

(b) MKE from the coastal model.

Figure 4. (Continued)

where $\Delta P_{k}$ is the layer thickness of layer $k$, and $u$ and $v$ the velocity components. The overline denotes the monthly average. Note that we have weighting of the layer velocities by the layer thickness, to account for the variation in time of the layer thickness. The EKE $\left(\mathrm{cm}^{2} / \mathrm{s}^{2}\right)$ in isopycnal coordinates is given as:

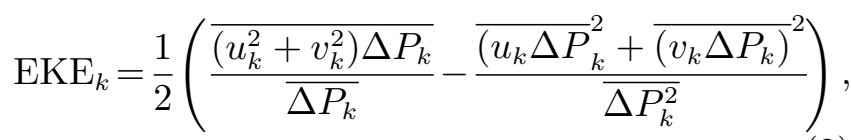

and explains the variability of the currents around the mean flow.

The MKE shows that the strength of the mean flow along the coast of southwest India is clearly better defined and stronger from the coastal model (figure 4b) than the Arabian Sea model (figure 4a). This is especially seen off the southern tip of India. The MKE is also more enhanced in the southern model domain, and is stronger in the coastal model, since the coastal model better resolves the energetic structure of the mesoscale features.

The EKE also differs in several locations, like off the southwest coast of India, where a narrow band of high EKE is seen in the coastal model (figure 4d), which is absent in the Arabian Sea model (figure 4c). In the southern part of the model domain high variability is also seen close to the coast in the coastal model, which is again absent in the Arabian Sea model. In addition an area of high variability is simulated between $8^{\circ}$ and $9^{\circ} \mathrm{N}$ and $72^{\circ}$ and $74^{\circ} \mathrm{E}$ in the coastal model which is weaker in the Arabian Sea model. When comparing the variability in the two models we can conclude that the coastal model is more energetic.

Simulated surface currents, sea surface temperature (SST) and salinity from the coastal model (figure 5) also show the impact of nesting. The solution in the nesting zone is not realistic since it becomes smoothed by the impact of the external nesting condition.

The impact of increasing the horizontal resolution is also seen in the surface flow for the Arabian Sea model which is smoother than the flow simulated by the coastal model (figure 5). The gyres and whirls resolved in the subsurface layer is also a result of increasing the resolution (figure 6). We can conclude that there is clearly a benefit of increasing the resolution as we better resolve the energetic structures of the mesoscale features. 


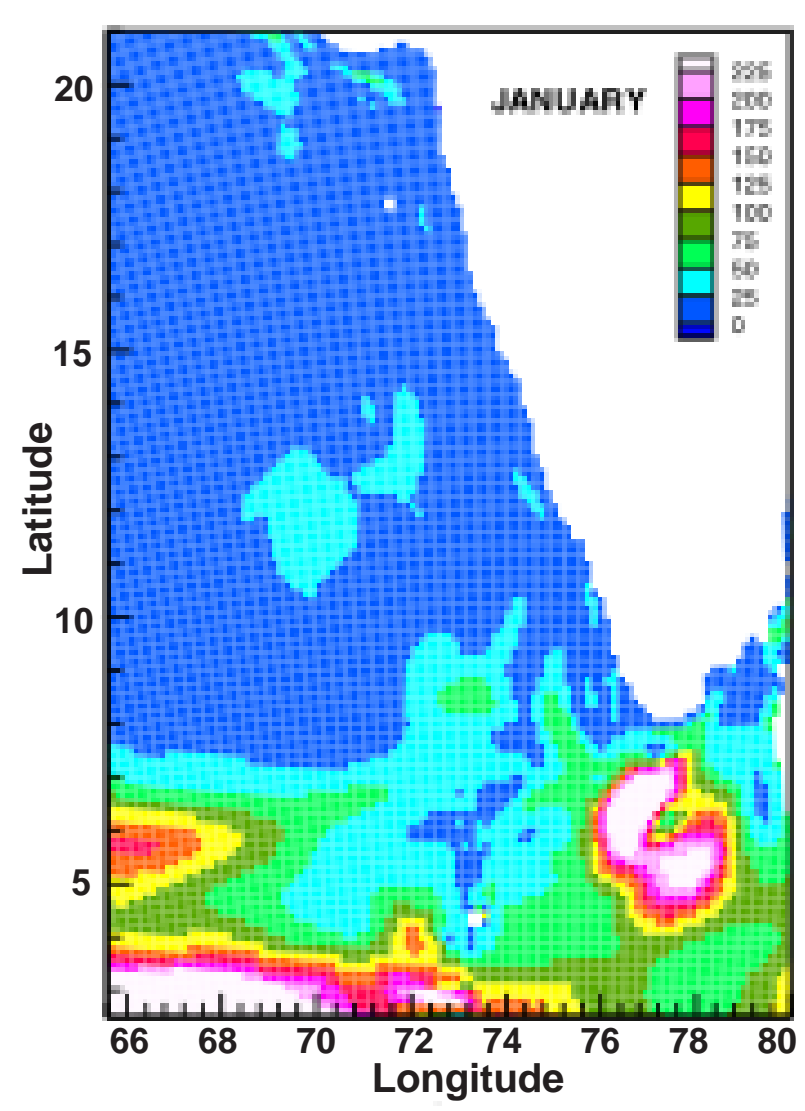

(c) EKE from the Arabian Sea model.

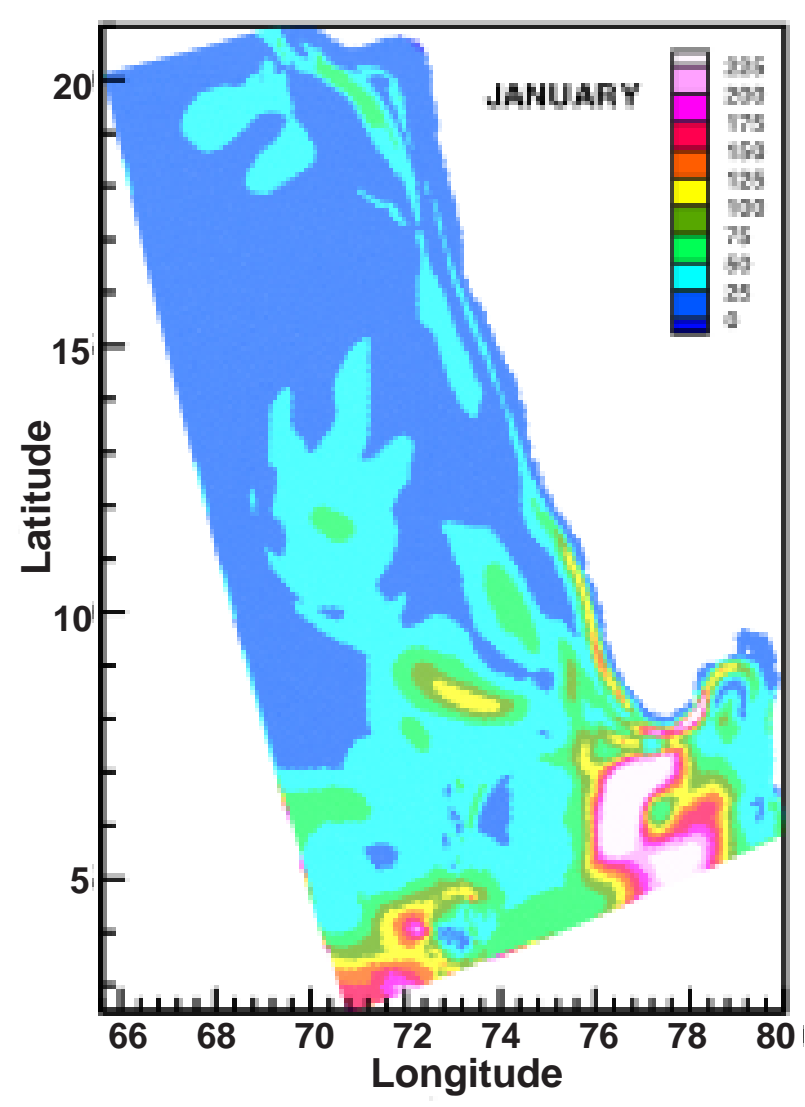

(d) EKE from the coastal model.

Figure 4(a-d). Mean ( $\mathrm{a}$ and b) and eddy kinetic energy $\left(\mathrm{cm}^{2} / \mathrm{s}^{2}\right)$ (c and d) from the Arabian Sea model (left) and the coastal model (right).

\section{Results and discussion}

\subsection{Surface and subsurface circulation}

The West Indian Coastal Current (WICC) (Shetye et al 1991) is simulated flowing south along the coast during the SW monsoon, between April and September (figure 5b). The current intensifies with the increase of the SW monsoon and speeds of $25-30 \mathrm{~cm} / \mathrm{s}$ are simulated in July during the peak of the SW monsoon. The current also intensifies, both in amplitude and spatial extent, as it flows southward. North of $14^{\circ} \mathrm{N}$ the current is narrow, but widens and reaches a spatial extent of $150 \mathrm{~km}$ flowing southward, which is in agreement to Shetye et al (1990) observations using hydrographic sections. South of $10^{\circ} \mathrm{N}$ it reaches a spatial extent of $450 \mathrm{~km}$. South of $7^{\circ} \mathrm{N}$ the WICC turns towards the coast and flows in a southeast direction, with the wind direction as seen from the NCEP forcing fields (figure 7).

In September the WICC starts reversing, and flows northward during the NE monsoon, between October and March, with speeds of $30 \mathrm{~cm} / \mathrm{s}$ during December/January (figure 5a). In the southern part of the coastline, between $8^{\circ}$ and $13^{\circ} \mathrm{N}$ the current is about $200-250 \mathrm{~km}$ wide, and carries low salinity Equatorial Surface Water, (figure 5c), which is consistent with Shetye et al (1991) observations using ship sections between December 1987 and January 1988. The current narrows as it flows northward, and is restricted to the continental slope at the northern part of the coastline. At $20^{\circ} \mathrm{N}$ it is about $40-50 \mathrm{~km}$ wide.

Below the reversing WICC we simulate a weak undercurrent of opposite direction with speeds between 0 and $10 \mathrm{~cm} / \mathrm{s}$, flowing northward following the shelf, during the SW monsoon (figure 6). This current is simulated between May and October with a width of $50 \mathrm{~km}$, reaching $100 \mathrm{~km}$ between $11^{\circ}$ and $14^{\circ} \mathrm{N}$ during July and August. The downward tilt of isopycnals in the subsurface layers for August (figure 8), also indicates the presence of this poleward undercurrent. Temperature characteristics associated with the flow range between $18^{\circ}$ and $20^{\circ} \mathrm{C}$, and compare well to Johannessen et al (1981) observations (figure 8, July), and also to Antony (1990) observations. The waters associated with the undercurrent appear to be $0.5^{\circ}-1.0^{\circ} \mathrm{C}$ warmer and 0.2-0.4 psu less saline (figure 9) than the waters offshore. Salinities associated with the 


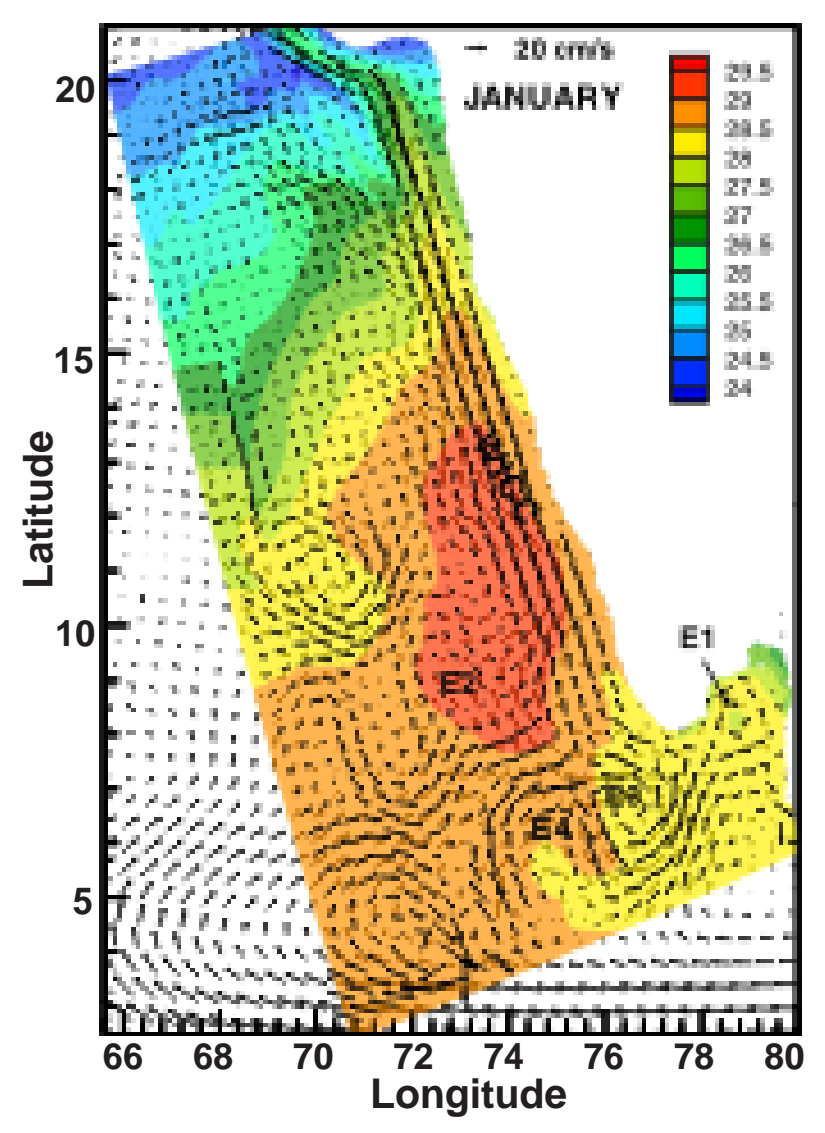

(a) SST and circulation in January.

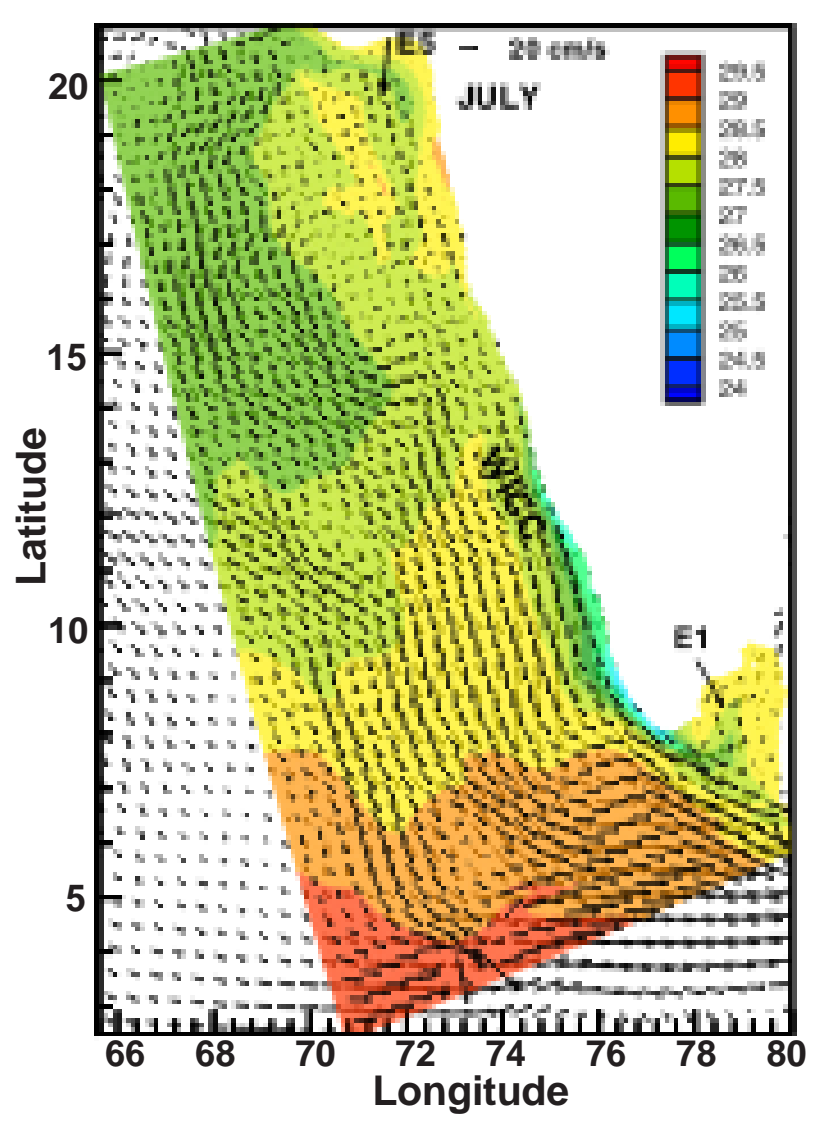

(b) SST and circulation in July.

Figure 5. (Continued)

undercurrent also appear to be lower along the southern sections (figure 9), between Cochin and Cape Comorin, than further north. Salinities are simulated down to 34.7 psu off Cochin and Quilon during the peak of the SW monsoon, and slightly higher 35-35.1 psu, off the Kasaragod and Karwar sections, which indicates transport of the less saline Bay of Bengal water northward. The simulated salinities compare well with Antony (1990) observations of a salinity minimum associated with the flow, ranging between 35.14 and 35.4 psu, along a hydrographic section at $15^{\circ} \mathrm{N}$, and Shetye et al (1990) observations of salinities less than $35 \mathrm{psu}$, hugging the continental shelf.

The undercurrent appears to decrease (figure 10, right) with an increase in the strength of the WICC. The undercurrent is simulated strongest off Quilon and Cochin during the SW monsoon, and weaker further north along the Karwar section. The WICC is weaker along Quilon and Cochin compared to the Kasaragod section for the same period. This was explained by Muraleedharan et al (1995) who proposed that the strength of undercurrents appears to be related to the surface current. The undercurrent feeds the surface current by vertical transport of subsurface water to the surface. Theoretical studies have shown that the presence of a shelf tends to slow down the undercurrent as the shelf induces a baroclinic component towards the equator (Antony 1990). Along the west coast of India the shelf width increases towards the north (figure 1) and therefore this might be a possible explanation of the decrease of the undercurrent towards the north as indicated above.

During the NE monsoon the undercurrent reverses direction and is simulated flowing southward. The undercurrent is present south of Karwar between December and March, with speeds between 5 and $10 \mathrm{~cm} / \mathrm{s}$ (figure 6). The southward flowing undercurrent intensifies with the monsoon period and reach values up to $10 \mathrm{~cm} / \mathrm{s}$ during January/February, and is simulated below 50-100 m (figure 10). The existence of an undercurrent in February was also suggested by Antony (1990) from hydrographic data from a section along $15^{\circ} \mathrm{N}$. From this we conclude that there exists a weak undercurrent of opposite direction to the WICC also during the NE monsoon, which is best defined south of $14^{\circ} \mathrm{N}$. 


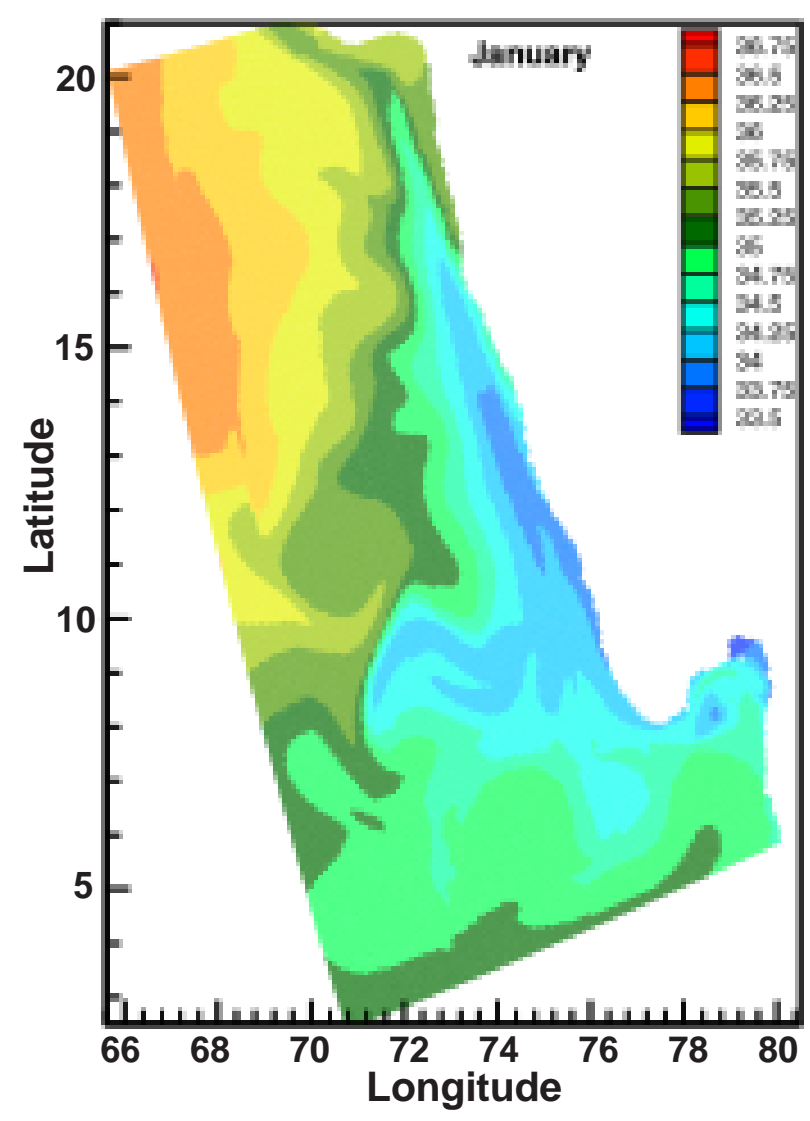

(c) Salinity in January.

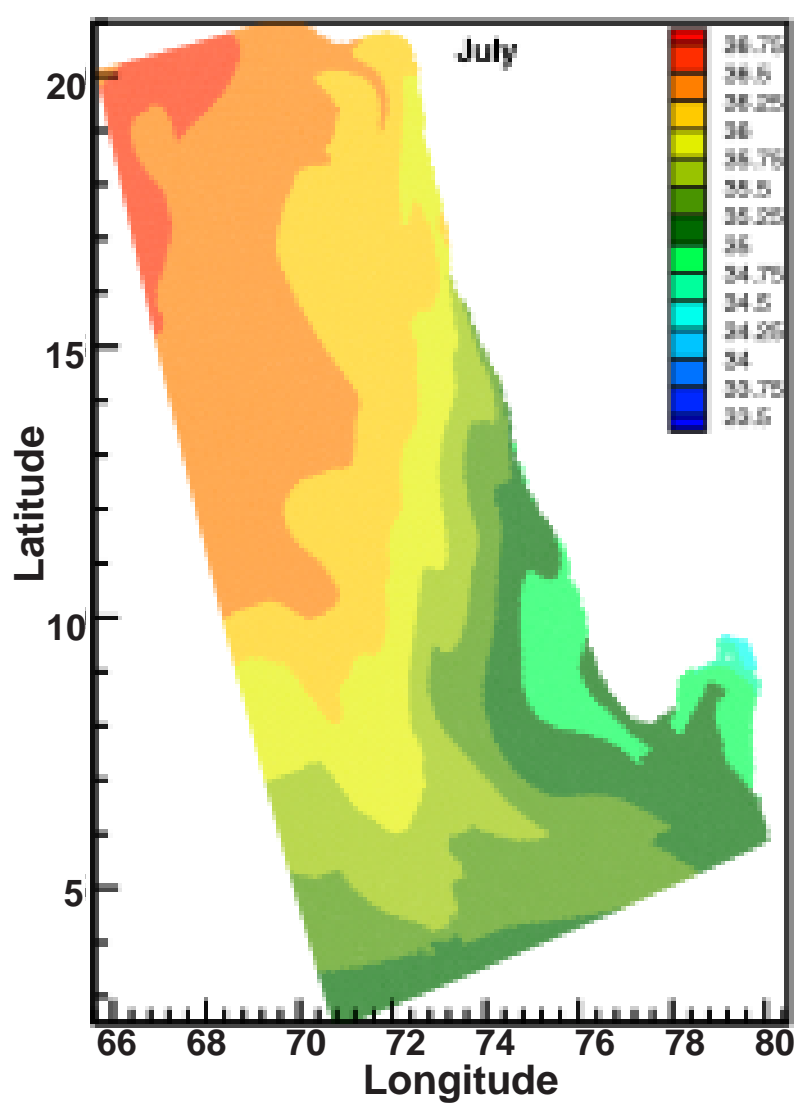

(d) Salinity in July.

Figure 5(a-d). Distribution of temperature $\left({ }^{\circ} \mathrm{C}\right)$, surface circulation and salinity (psu) during the NE (left) and SW monsoon (right). Vectors plotted in the coloured area represent the circulation in the coastal model, and vectors in the white area represent the circulation in the Arabian Sea model. (Every 7th vector is plotted for the coastal model, and every 3rd for the Arabian Sea model.)

\subsection{Mesoscale eddies}

With the increase of horizontal resolution also the eddy activity increases as seen from the EKE (figure 4, bottom). Only a brief presentation of the location and size of the most persistent eddies is given.

One of the eddies simulated is the anticyclonic eddy (E1) south of India, at $8^{\circ} \mathrm{N}$ and $78.5^{\circ} \mathrm{E}$, which first appears in July with a diameter of about $80-90 \mathrm{~km}$ (figure 5b). It increases in September and reaches a diameter of about $200 \mathrm{~km}$, before it decays in October (not shown). E1 again appears during the NE monsoon and is also simulated between January and March with a diameter of $80-100 \mathrm{~km}$ (figure $5 \mathrm{a}$ ). The anticyclonic eddy (E2) is identified in January from high EKE (figure $4 \mathrm{~d}$ ), centered at $8^{\circ} \mathrm{N}$ and $73.5^{\circ} \mathrm{E}$. This eddy is simulated between October and February with a diameter of $300-350 \mathrm{~km}$, in both the surface (figure 5a) and subsurface layer (figure 6a). The cyclonic eddy (E3), which is also identified from the EKE (figure $4 \mathrm{~d}$ ) is centered at $6^{\circ} \mathrm{N}$ and $77^{\circ} \mathrm{E}$, and simulated from September until February when it weakens and dissapears, and is present in both the surface and subsurface layer. The anticyclonic eddy (E4) is simulated between October and February, with a diameter of $300-400 \mathrm{~km}$, in the surface and subsurface layers, and forms an eddy pair with the cyclonic E3 eddy. It is clearly affected by the shallow shelf located between $72^{\circ}$ and $74^{\circ} \mathrm{E}$ known as the Laccadive Ridge, as its western boundary follows the ridge. A small cyclonic eddy (E5) is simulated in the northern model domain, at $19.5^{\circ} \mathrm{N}$ and $72^{\circ} \mathrm{E}$ and located on the continental shelf. It is first simulated in June/July with a diameter of $50 \mathrm{~km}$ (figure 5), but increases during August/September to $150 \mathrm{~km}$, before it disappears. It also extends down to the subsurface layer, although weaker and smaller.

In the subsurface layer (figure 6) the number of eddies seems greater than in the surface layer. A lot of the eddy activity in this layer seems to follow the continental shelf, hence topographic steering seems important, but will not be further discussed in this study. 

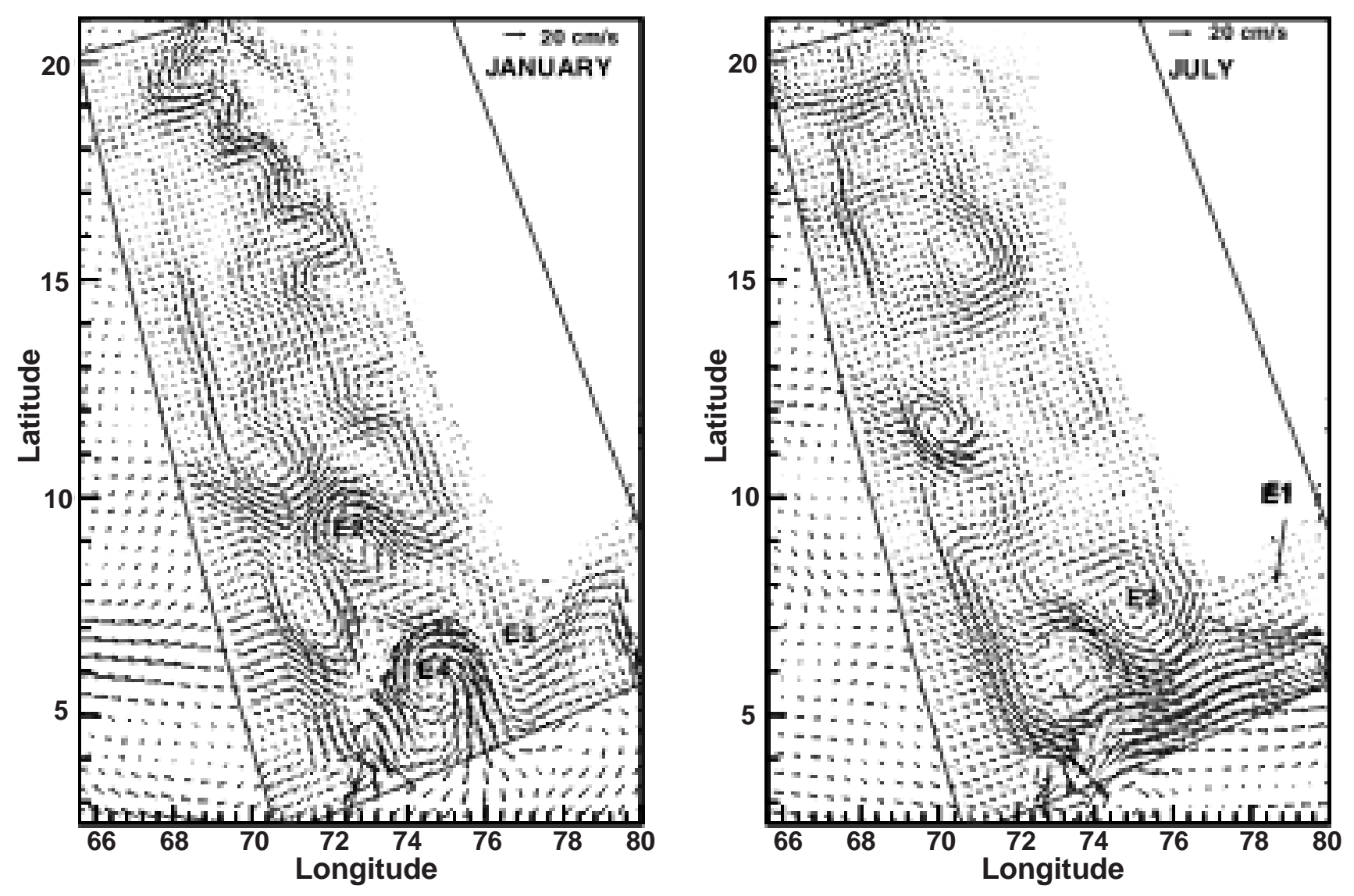

Figure 6. Circulation in layer 2 from the coastal model for the NE monsoon (left) and SW monsoon (right). Every 5th vector is plotted. Note that the reference vector is slightly longer than in figure 4 for the circulation in the surface layer, to better map the circulation.

Above the core of the undercurrent a sharp upward tilt of the isopycnals towards the coast indicates upwelling (figure 8), and will be discussed in the following section.

\subsection{Upwelling}

The distribution of SST (figure 5a and b) and salinity (figure $5 \mathrm{c}$ and d) off the west coast of India during the monsoon periods, shows that the temperature weakens northward together with an increase in the salinity. Along the coastline, a belt of colder upwelled water is seen during the SW monsoon between the southern tip of India and $13^{\circ} \mathrm{N}$. The temperature difference is about $3^{\circ}-4^{\circ} \mathrm{C}$ between the near coastal and offshore waters in the surface layer. The belt of upwelling is simulated along the coast during the SW monsoon, from Ratnagiri to Cape Comorin, extending $150-200 \mathrm{~km}$ offshore. The cold upwelled water is transported into the Bay of Bengal during the SW monsoon with the Indian Monsoon Current. With the cold upwelled water more saline water is brought to the surface and the salinity increases. Just off the coast the salinity is during the SW monsoon $34.75-35$ psu, and offshore above 35.5 psu. Low salinity water, below $33 \mathrm{psu}$ is simulated during the NE monsoon along the coast, and above 35.5 psu offshore, indicating westward penetration of low salinity Bay of Bengal water.

Vertical sections characterize warm (figure 8) and high saline (figure 9) surface waters and colder and less saline subsurface waters during July-October between Ratnagiri and Karwar, indicating the transport of low salinity Bay of Bengal water. The rest of the year the salinity is less in the surface than in the subsurface layer. Along the sections between Kasaragod and Cape Comorin warmer and less saline water, compared to the subsurface, is simulated throughout the year. These results compare well with Johannessen et al (1981), who demonstrated upwelling by the shoreward lifting of the isolines for the sections Ratnagiri to Tuticorin during August 1974 (figure 8, right), and reported that the behavior and distribution of some fish species are directly restricted to the upwelling of colder, oxygen depleted water together with a peak in plankton concentration. 

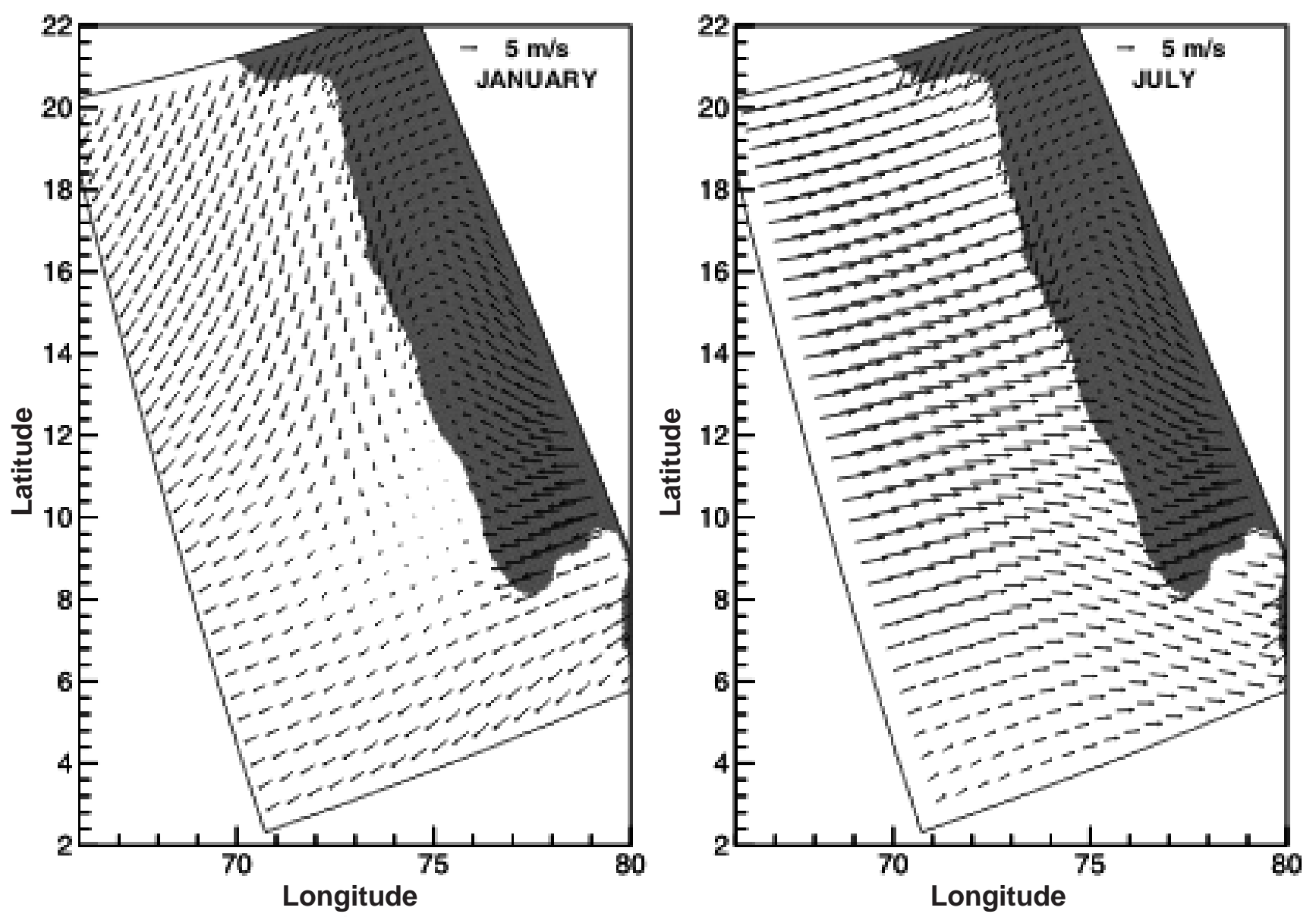

Figure 7. Monthly averaged NCEP forcing winds during the peak of the NE monsoon, January (left) and SW monsoon, July (right). (Every 10th vector is plotted.)

Time series of SST for selected points from the 7 sections in figure 1 (denoted by circles) indicate that SST starts decreasing as early as April (figure 11). Upwelling is most intense between Cochin and Quilon, which is consistent with Johannessen et al (1981) results. Temperatures are simulated less than $24^{\circ} \mathrm{C}$ at the beginning of June, indicating a drop of $3^{\circ}-4^{\circ} \mathrm{C}$. Shetye et al (1990) experienced a weak drop of $2.5^{\circ} \mathrm{C}$ in June-August 1987 from their hydrographic study, which is less than seen in 1974. Also Kasaragod and Cape Comorin show a significant drop in SST of $24.5^{\circ}$ and $25.5^{\circ} \mathrm{C}$ respectively. Less upwelling is however simulated in the Ratnagiri, Karwar and Tuticorin sections. During this intense upwelling the local meridional wind component is strongly southward. The upwelling period is simulated to the end of September. However, in July an increase of $4^{\circ} \mathrm{C}$ is simulated for the sections between Kasaragod and Cape Comorin, which is due to a reversal of the local meridional wind component to the north (figure 11f). This increase in SST is also seen as an increase in the SLA, a drop in salinity and a deepening of the mixed layer.
The upwelling of cold water in June leads to a lowering of SLA to $4-6 \mathrm{~cm}$, and suggests the upwelling to start in April. In May, SLA increases before it again drops and reaches a maximum of $16 \mathrm{~cm}$ in June. Upwelling is observed to be weak during the beginning of its onset, but as the monsoon intensifies it increases and reaches maximum SLA of $15-20 \mathrm{~cm}$ in mid-June, in the areas closest to the coast. An increase in the salinity of $1 \mathrm{psu}$ is simulated during the NE monsoon and is observed at all 7 locations, with Cochin and Quilon experiencing the maximum increase.

These results coincide with Johannessen et al (1981) observations of a maximum increase in Zooplankton during July/August, which again follows the pattern of upwelling with the uplifting of isolines which reach its most shallow position between July and October. Also the mixed layer depth decreases, and reaches a depth of $20 \mathrm{~m}$ between April and September, which is a reduction of $40-50 \mathrm{~m}$ compared to the depth during the NE monsoon.

During the NE monsoon the surface water along the west coast of India is warmer than during 

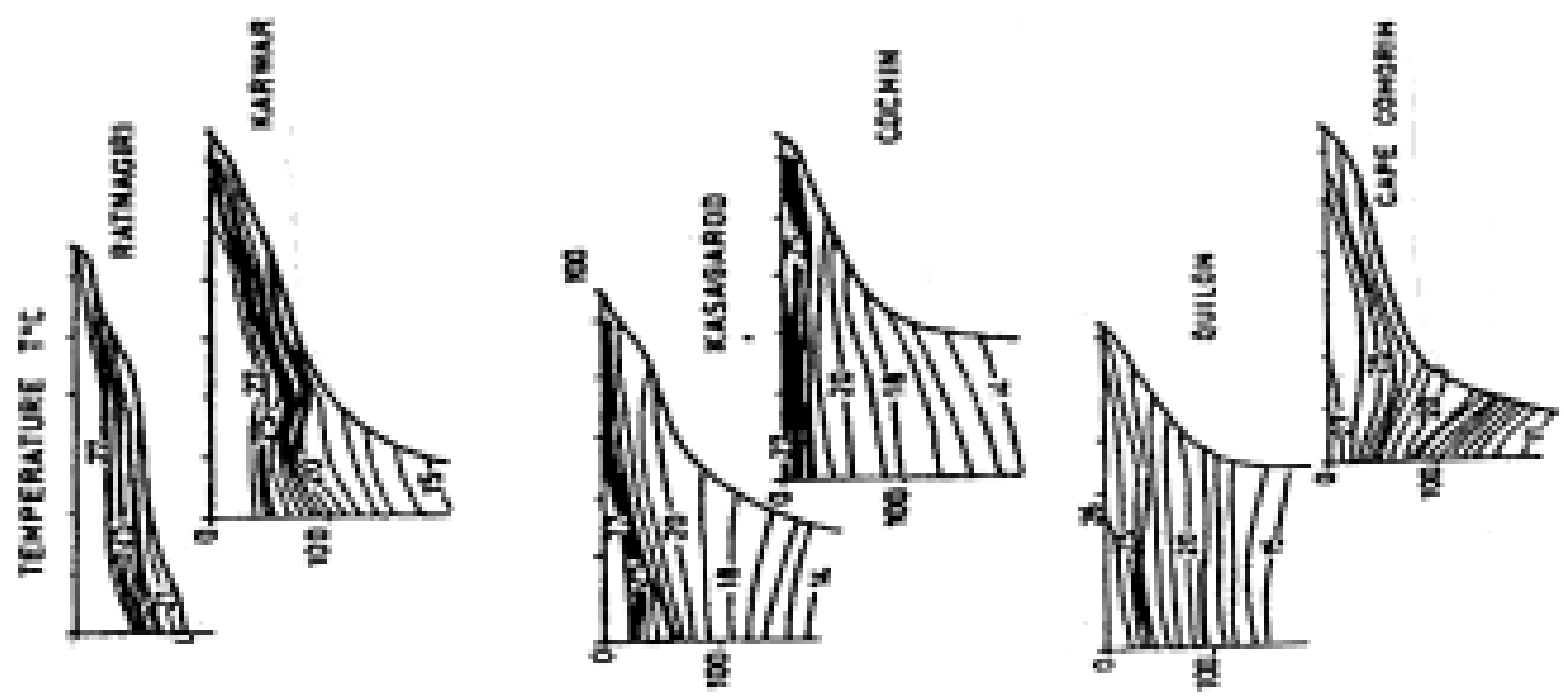

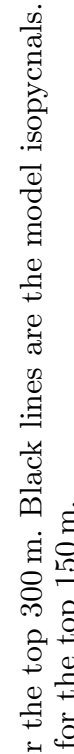
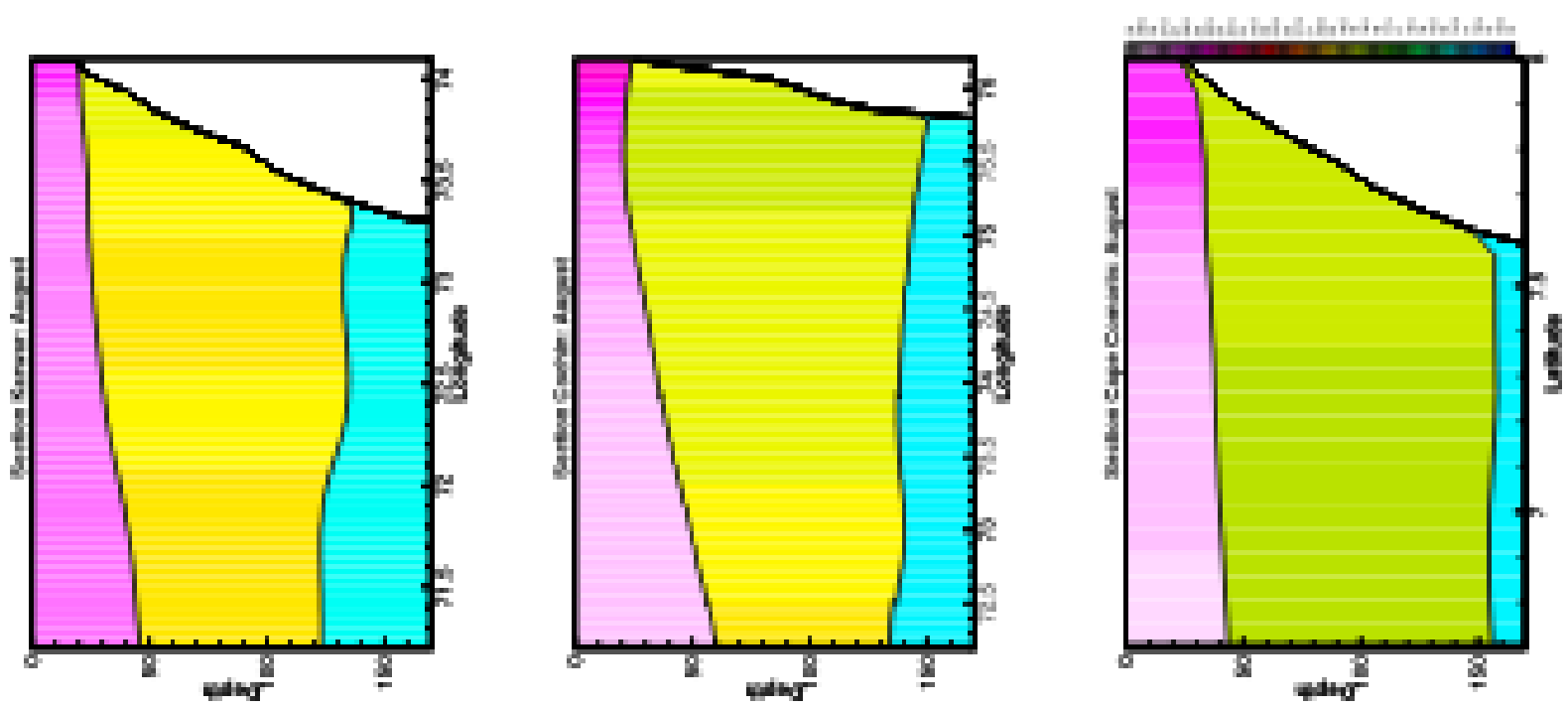

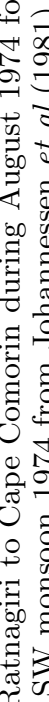
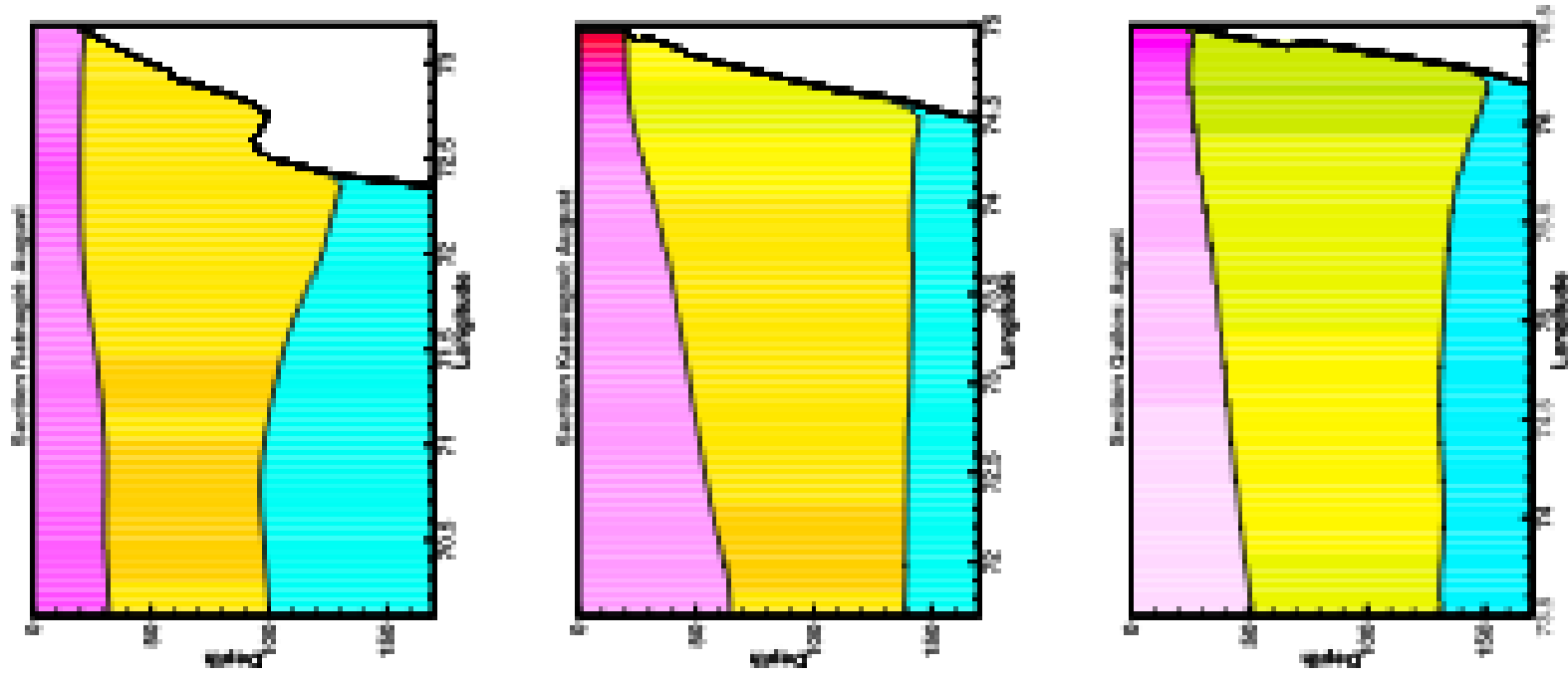

द्व

$\rightarrow 30$

.

过

ชิ

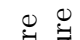

䓠

웡 है

Ð

业

क

$\infty \stackrel{+}{\infty}$

$\bigcup_{3}^{\infty} \frac{\pi}{0}$ 

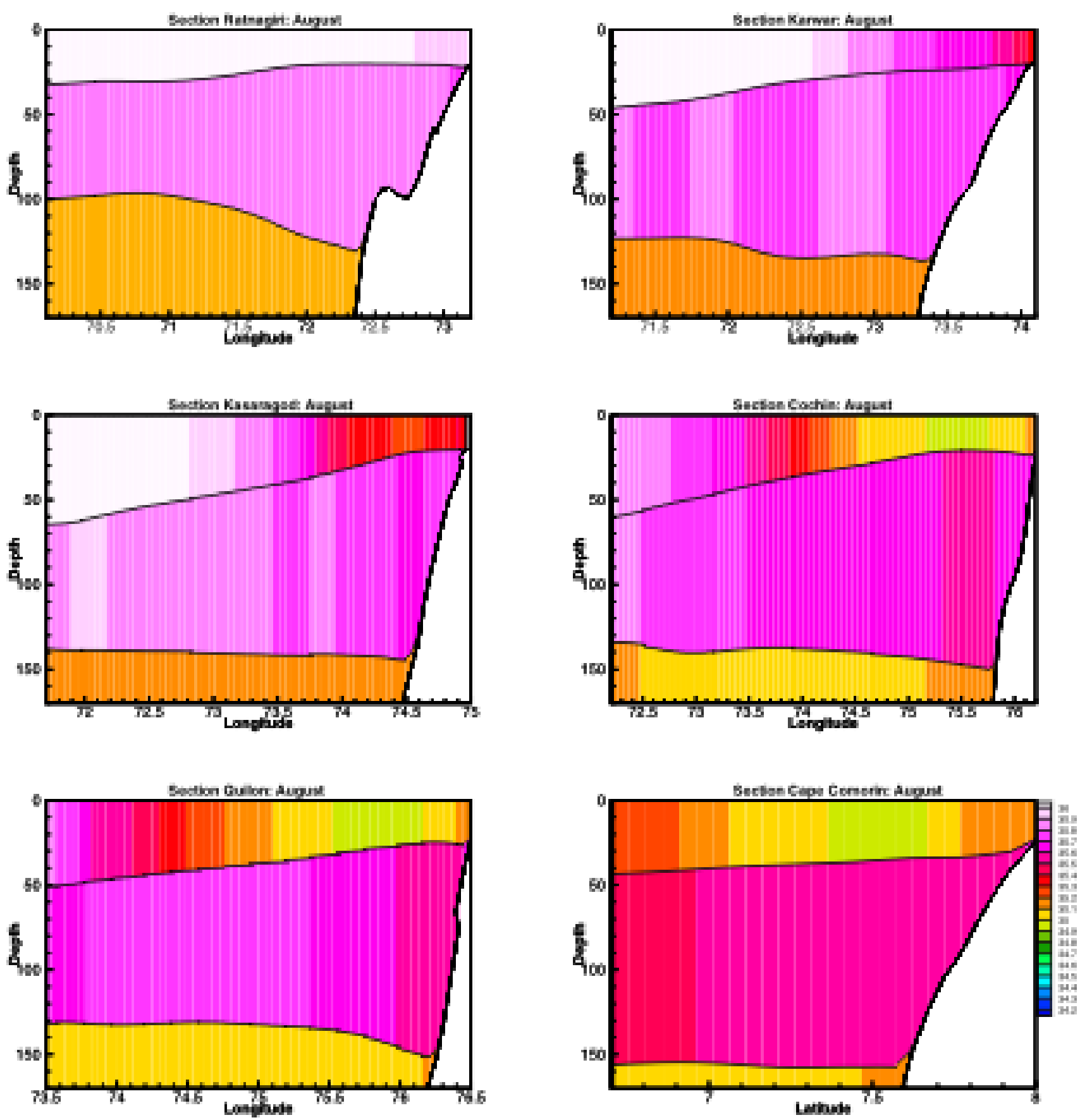

Figure 9. Salinity (psu) sections from Ratnagiri to Cape Comorin during August 1974.

the SW monsoon upwelling period (figure 5). The salinity decreases and the temperature increases, and together with the downward tilting of isopycnals in the surface layer (figure 10) this indicates downwelling. SST starts increasing in January and reaches $30^{\circ} \mathrm{C}$ in April (figure 11) before it again drops. SLA also starts increasing in January and reaches $10 \mathrm{~cm}$ between February and April, which is also the case for the mixed layer depth, which reaches a depth of $60-70 \mathrm{~m}$. Downwelling is also seen along the vertical sections of temperature and salinity (not shown).

\subsection{Forcing mechanism}

Knowledge of the local wind is essential in order to understand the western boundary coastal current off the southwest coast of India. During the SW monsoon the overall direction of the winds over the northern Indian Ocean is from the southwest. However, considerable departures from this direction appear from place to place, as seen in figure 7 which shows the monthly averaged NCEP winds used as forcing. The wind varies during the SW monsoon between west-southwest in 

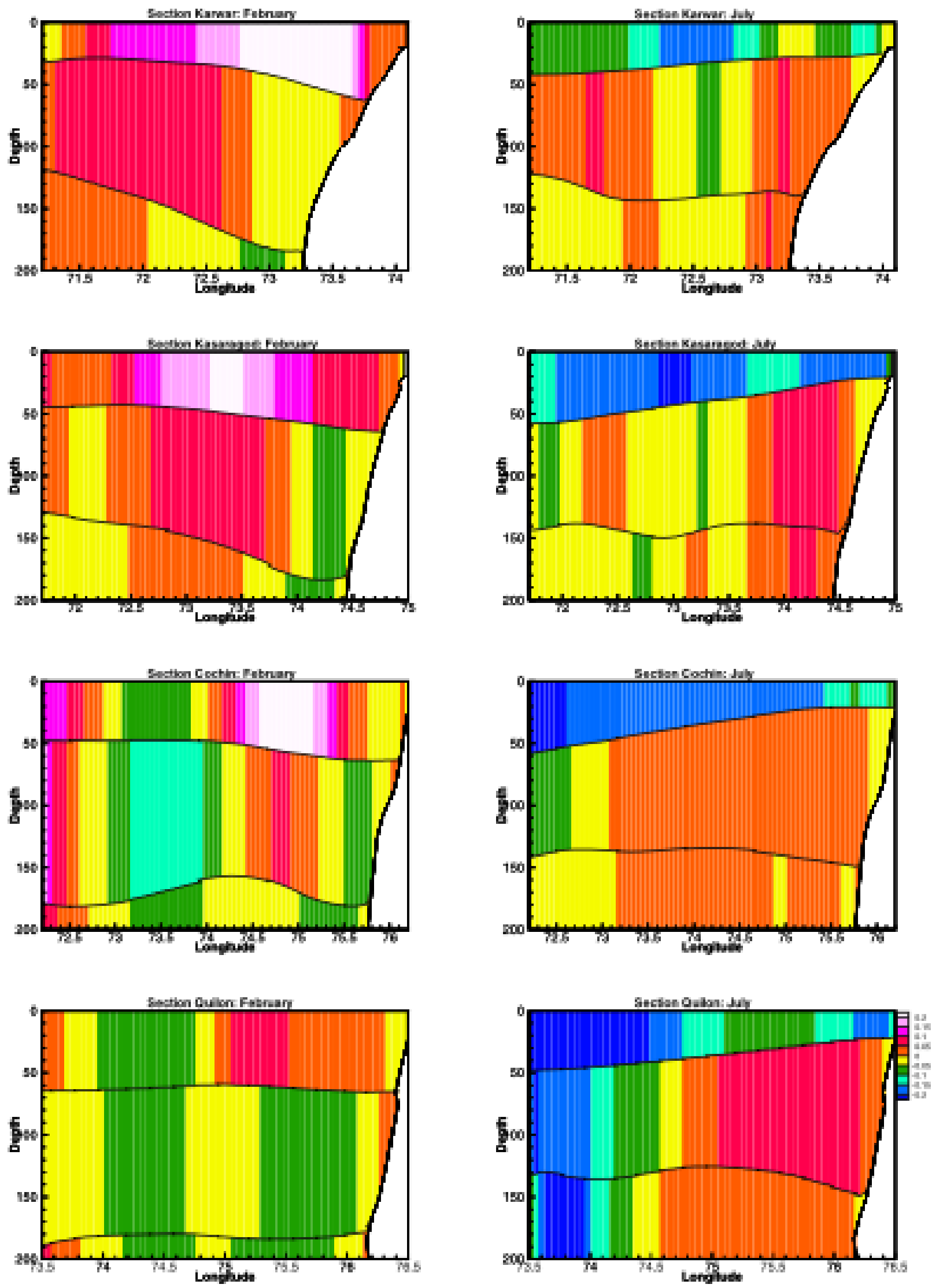

Figure 10. Meridional velocity (m/s) during February (left) and July (right) 1974 for the sections Karwar, Kasaragod, Cochin and Quilon. 
a) Sea surface temperature

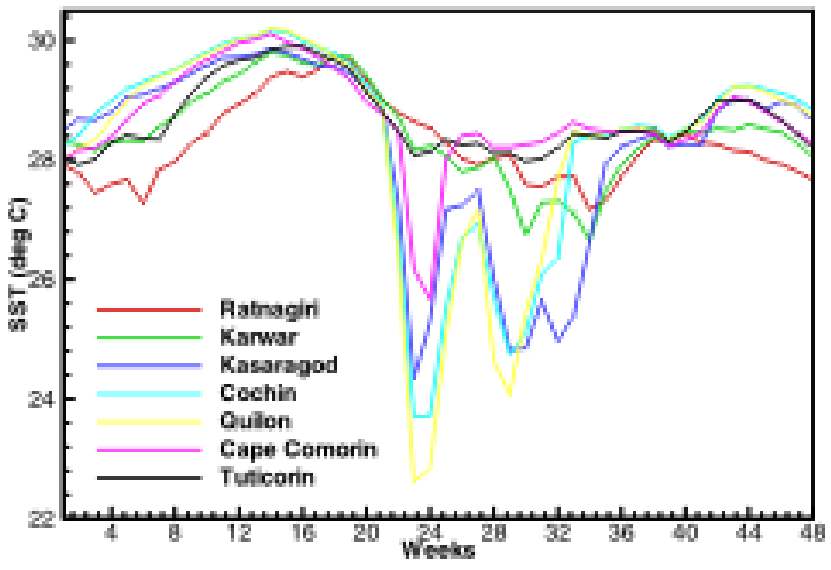

c) Sea level anomalies

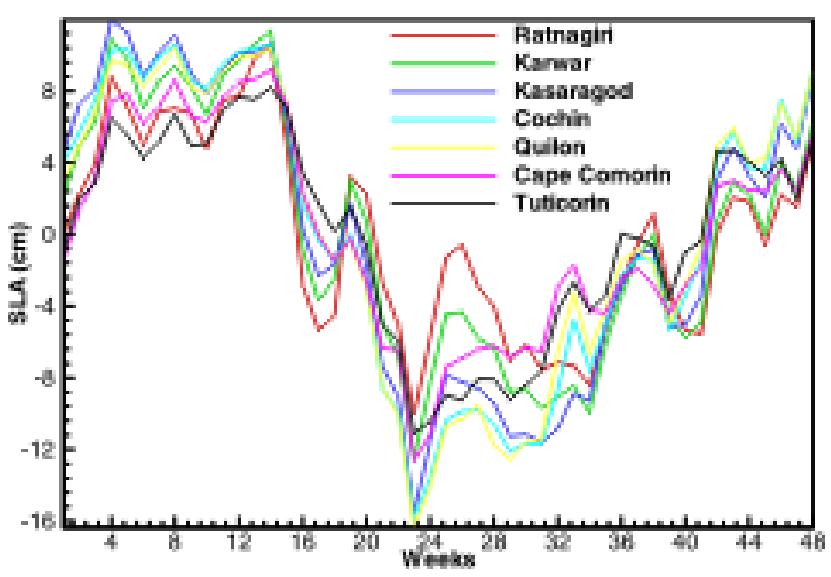

e) Zonal velocity

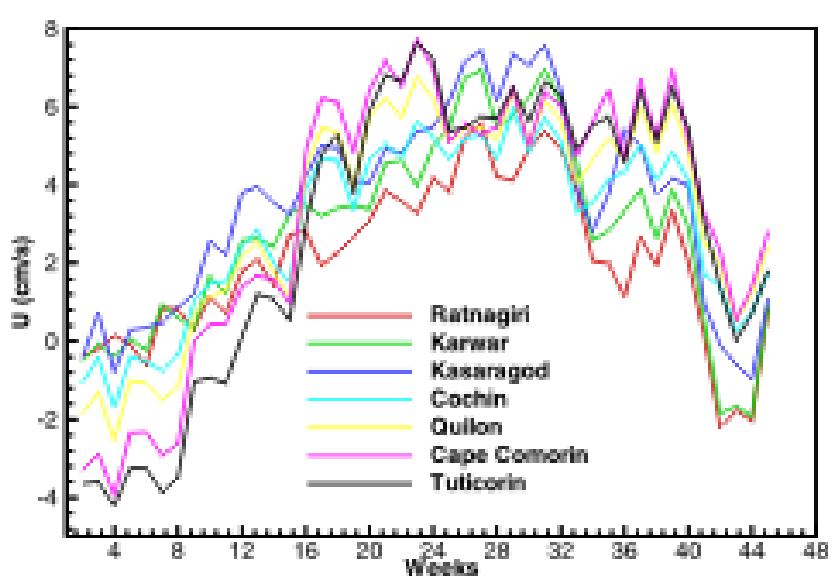

b) Salinity

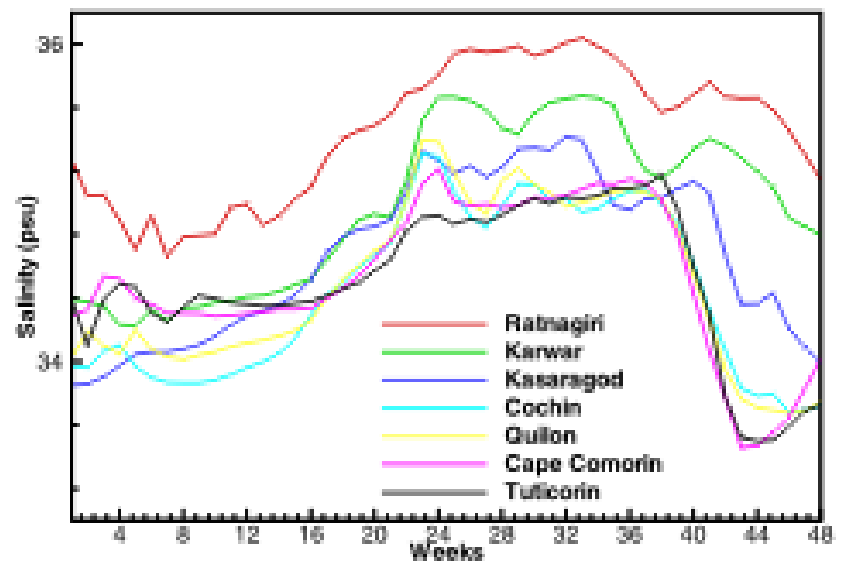

d) Mixed layer depth

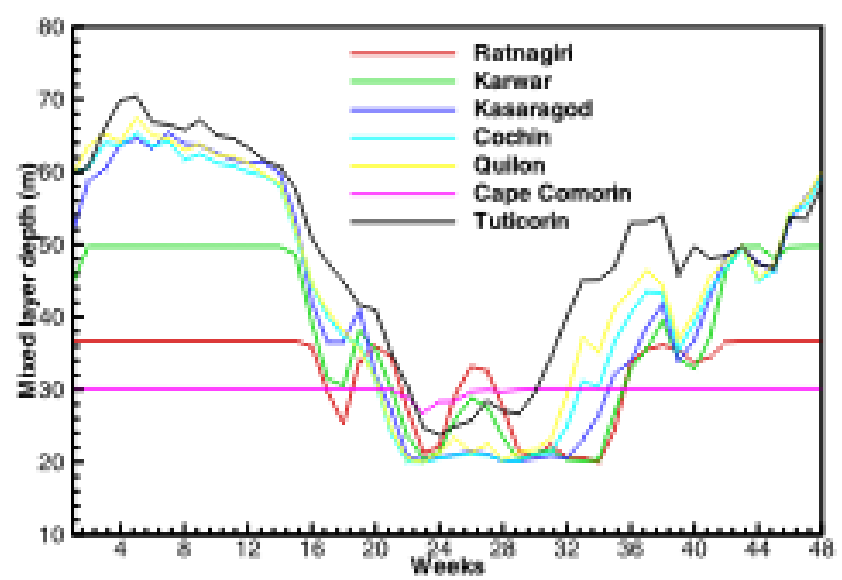

f) Meridional velocity

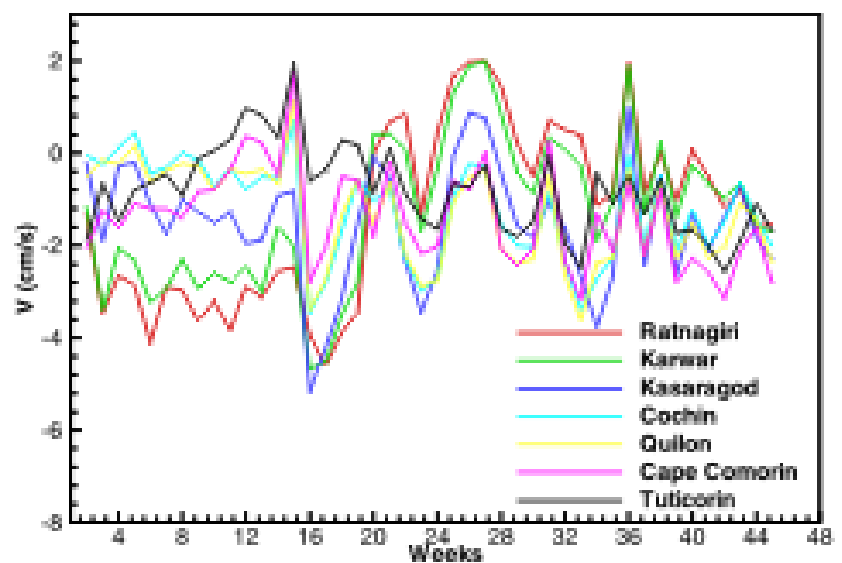

Figure 11. Time series of SST, salinity (top), SLA, mixed layer thickness (middle), zonal and meridional velocity (bottom) at 7 locations between Ratnagiri and Tuticorin.

the north to west-northwest in the south. During the NE monsoon the winds are generally northeasterly over the northern Indian Ocean. Variations are seen, and the wind also blows from the north-northeast in the north to east in the south. During the transition periods, March/April and October/November the wind varies from northnorthwest. 

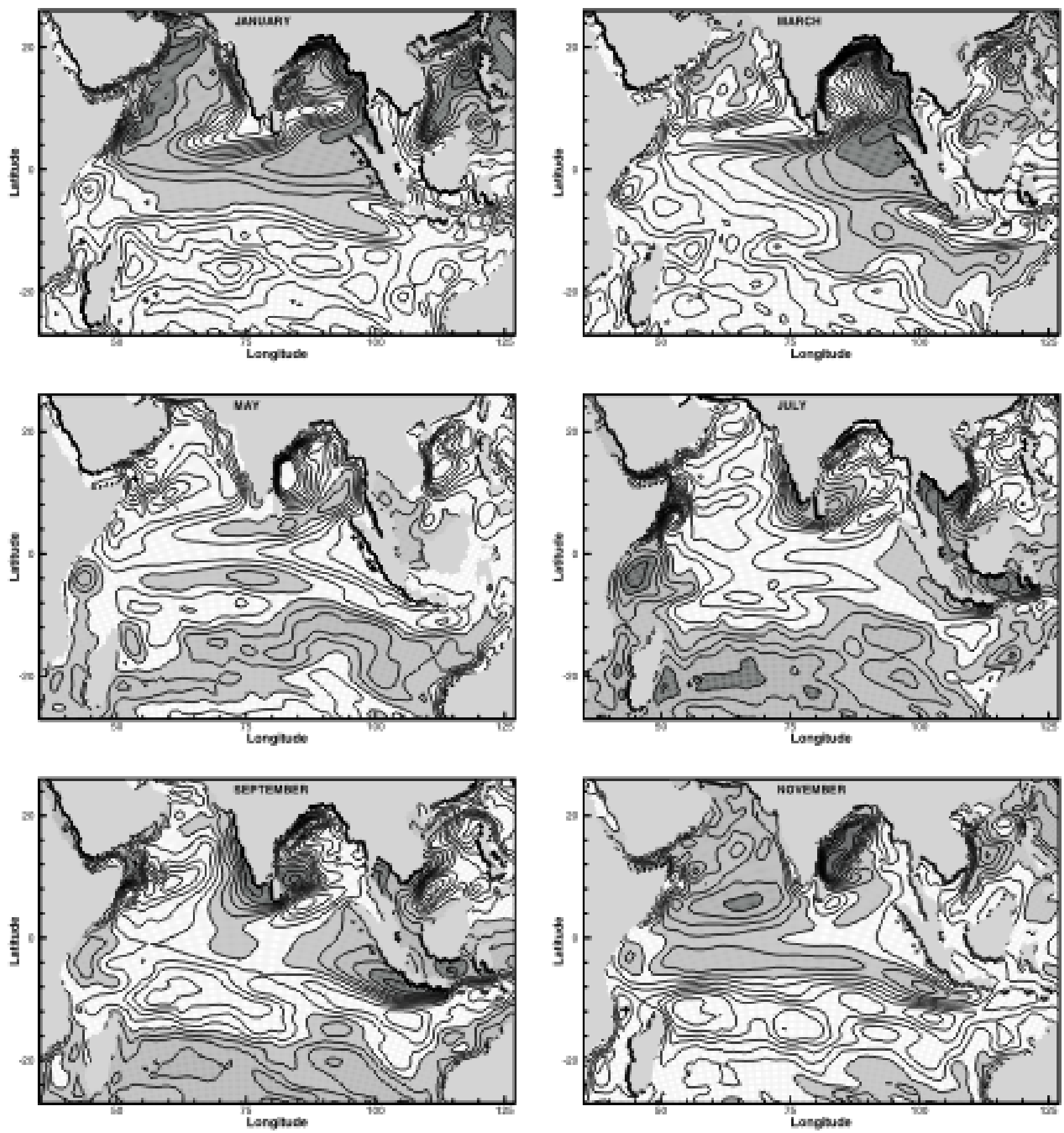

Figure 12. Monthly averaged SLA in cm over 40 years as simulated from the Indian Ocean model (Haugen et al 2002a). Every second month is shown. Negative anomalies are shaded. (Contour interval is $2 \mathrm{~cm}$.)

The driving force of the upwelling has been discussed by several investigators. The wind direction from the west as described above is consequently not in favour of intensifying a wind driven upwelling. Johannessen et al (1981) stated that due to high winds during the SW monsoon, the WICC is speeded up and the associated tilt of the isolines increases. Therefore, it is likely that upwelling is not only associated with the local wind, but also with large scale monsoonal conditions which drive the anticyclonic Arabian Sea gyre. This strengthens the indication that remote forcing also influences the surface current. However, south of $7^{\circ} \mathrm{N}$ the WICC flows with the wind in a southeasterly direction. Shankar and Shetye (1997) indicated that remotely forced Kelvin waves favor the formation of upwelling off the western coast of India. 
From a 40-years simulation using the Indian Ocean model (Haugen et al 2002a) the propagation of upwelling (seen as negative SLA) and downwelling (seen as positive SLA) Kelvin and Rossby waves were discussed (figure 12). During January and February upwelling Kelvin and Rossby waves are simulated along the equator and downwelling Kelvin and Rossby waves are simulated off both coasts of India (figure 12, top). The abrupt change in the wind direction along the equatorial region during April-May causes a change in the upper ocean, depressions in the thermocline along with a rise in the ocean surface, which triggers eastward propagating downwelling Kelvin waves (Yang et al 1998). Some of the energy of the Kelvin wave moves along the eastern coast as two coastal Kelvin waves, one northwards and one southward. After the coastally trapped Kelvin waves reach the coast of India they radiate westward propagating downwelling Rossby waves to the interior of the Arabian Sea (figure 12, top). The coastally trapped downwelling Kelvin waves which propagate along the western coast of India are likely to drive the northward flowing WICC during the NE monsoon.

With the start of the SW monsoon, downwelling Kelvin waves are excited. In May (figure 12, middle) simulated downwelling Kelvin waves have reached the eastern boundary of the Indian Ocean, and downwelling Rossby waves are again being radiated offshore. In June negative anomalies are simulated off both coasts of India. These upwelling Rossby waves are radiated into the Arabian Sea. The coastally trapped upwelling Kelvin waves which have propagated around the Bay of Bengal, rounds the edge of India and are likely to drive the southward flowing WICC during the SW monsoon.

Theoretical models have shown that an equatorward wind along the eastern boundary drives an offshore Ekman drift at the ocean surface and a return flow underneath (Antony 1990). This is accompanied by a surface equatorward jet and a poleward undercurrent that decays offshore. The theoretical model developed by Yoshida (1967) stresses the importance of the poleward undercurrent and reinforces that coastal undercurrents are dynamically related to upwelling. Recent studies show that major upwelling centers in the world (off Oregon, northwest Africa and off Peru) support the conceptual model and highlight an associated feature of the upwelling system, viz., the poleward undercurrent (Muraleedharan et al 1995).

\section{Conclusion}

A high resolution model has been implemented for the first time to study the seasonal circu- lation and coastal upwelling off the southwest coast of India. Along the southwest coast the dominant coastal current is the West Indian Coastal Current which is well simulated and described, together with the weaker undercurrent of opposite direction. The undercurrent was simulated flowing northward during the SW monsoon, and southward south of Karwar during the NE monsoon.

Upwelling starts at the beginning of April, and is persistent until September/October, which is consistent with Johannessen et al (1981) observations made during 1974, and also seen for the years 1971-1975. Upwelling is weak in the beginning and intensifies with the monsoon. Upwelling is simulated between Ratnagiri and Cape Comorin, and reaches $200 \mathrm{~km}$ offshore. It is most intense off Quilon, Cochin and then Kasaragod. The SST drops from $28^{\circ}-30^{\circ} \mathrm{C}$ to less than $24^{\circ} \mathrm{C}$ off Cochin and Quilon, and the mixed layer depth decreases from $60 \mathrm{~m}$ during the transition periods to $20 \mathrm{~m}$. A downwelling period is associated with an increase of SST of $1^{\circ}-2^{\circ} \mathrm{C}$, deepening of the mixed layer, decrease in salinity and downward tilting of the isolines in the surface layer between November and February. The downwelling is most intense between January and April.

From our study it is clearly seen that the upwelling off the southwest coast of India is not only associated with local wind. Previous investigations have suggested that large scale monsoonal conditions which drive the anticyclonic Arabian Sea gyre are a possible cause, together with remotely or locally forced Kelvin waves. The Indian Ocean model simulated coastally trapped downwelling Kelvin waves which drive the northward flowing WICC during the NE monsoon, and upwelling Kelvin waves which drive the southward flowing WICC during the SW monsoon (figure 12). These waves form the large intraseasonal signal seen in (figure 11), while the sudden change in SST and SLA during the SW monsoon was a result of changes in the local meridional component (figure 11f).

In addition poleward flowing undercurrents have been dynamically related to upwelling in other areas of the world. In conclusion our model simulation is reproducing well the coastal circulation and the dominant upwelling on the continental shelf off the southwest coast of india, and can be used to e.g., study the interannual variability for the NCEP period. Further studies will include a 40-years simulation using this validated model forced by the National Centers Environmental Prediction (NCEP) winds to study the interannual circulation and upwelling. 


\section{Acknowledgments}

Vibeke E J Haugen is supported by the Norwegian Research Council Ph.D Fellowship program, under contract $129247 / 730$. This work has received support from a grant of CPU time from the Norwegian supercomputing community (TRU) through a grant of computer time.

\section{References}

Antony M 1990 Northward undercurrent along west coast of India during upwelling - Some interferences; Indian Journal of Marine Sciences 19 95-1015

Banse K 1968 Hydrography of the Arabian Sea Shelf of India and Pakistan and effects on demersal fishes; Deep-Sea Res. 15 45-79

Bentsen M, Evensen G, Drange H and Jenkins A 1999 Cordinate transformation on a sphere using conformal mapping; Mon. Weather Rev. 127 2733-2740

Bleck R and Boudra D 1986 Wind-driven spin-up in eddyresolving ocean models formulated in isopycnic and isobaric coordinates; J. Geophys. Res. 91 7,611-7,621

Bleck R C, Rooth D H and Smith L 1992 Salinity-driven thermocline transients in a wind- and thermohalineforced isopycnic coordinate model; J. Phys. Oceanogr. 22 $1486-1505$

Bleck R, Hanson H, Hu D and Kraus R 1989 Mixed layerthermocline interaction in a three-dimensional isopycnic coordinate model; J. Phys. Oceanogr. 19 1417-1439

Bleck R and Smith L 1990 A wind-driven isopycnic coordinate model of the North and Equatorial Atlantic Ocean. 1. Model development and supporting experiments; $J$. Geophys. Res. 95 3273-3285

Browning G and Kreiss H 1982 Initialization of the shallow water equations with open boundaries by the bounded derivative method; Tellus 34 334-351

Browning G and Kreiss H 1986 Scaling and computation of smooth atmospheric motions; Tellus Ser A $\mathbf{3 6}$ 295-313

Gaspar P, Gregories Y and Lefevre J-M 1990 A simple eddy kinetic energy model for simulations of the oceanic ver- tical mixing: Tests at station Papa and long-term upper ocean study site; J. Geophys. Res. 95(C3) 16179-16193

Haugen V E and Evensen G 2002 Assimilation of altimeter and SST data into an ocean general circulation model in the Indian Ocean; Ocean Dynamics 52 133-151

Haugen V E, Johannessen O M and Evensen G 2002a Indian Ocean circulation. Part 1: Validation of the Miami Isopycnic Coordinate Ocean Model and Part 2: ENSO events during 1958-1998; J. Geophys. Res. 107 C5 101029-101057

Johannessen O M, Subbaraju G and Blindheim J 1981 Seasonal variations of the oceanographic conditions off the southwest coast of India during 1971-1975; FiskDir. Skr. Ser. HavUnders. 18 247-261

Legates D and Willmott C 1990 Mean seasonal and spatial variability in gauge-corrected, global precipitation; $J$. Climatology 10 111-127

Muraleedharan P, Ramesh-Kumar M and Gangadhara-Rao L 1995 A note on poleward undercurrent along the southwest coast of India; Cont. Shelf Research 15 165-184

Shankar D and Shetye S 1997 On the dynamics of the Lakshadweep high and low in the southeastern Arabian Sea; J. Geophys. Res. 97 12551-12562

Shetye S R, Gouveia A, Shenoi S S C, Michael G S, Almeida A and Santanam K 1990 Hydrography and circulation off the west coast of India during the southwest monsoon 1987; Deep-Sea Res. 48 359-378

Shetye S R, Shenoi S S C, Michael G S, Sundar D, Almeida A and Santanam K 1991 The coastal current off western India during the northeast monsoon; Deep-Sea Res. 38 1517-1529

Smith L, Boudra D and Bleck R 1990 A wind-driven isopycnic coordinate model of the North and Equatorial Atlantic Ocean. 2. The Atlantic basin experiment; $J$. Geophys. Res. 95 13105-13128

Stramma L, Fischer J and Schott F 1996 The flow field off southwest India at $8^{\circ} \mathrm{N}$ during the southwest monsoon of August 1993; J. Marine Res. 54 55-72

Yang J, Yu L, Koblinsky C J and Adamec D 1998 Dynamics of the seasonal variations in the Indian Ocean from Topex/Poseidon sea surface high and an ocean model; Geophys. Res. Letters 25 1915-1918

Yoshida K 1967 Circulation in the Eastern Tropical Oceans with special reference to upwelling and undercurrents; Japanese Journal of Geophysics 4 1-75 